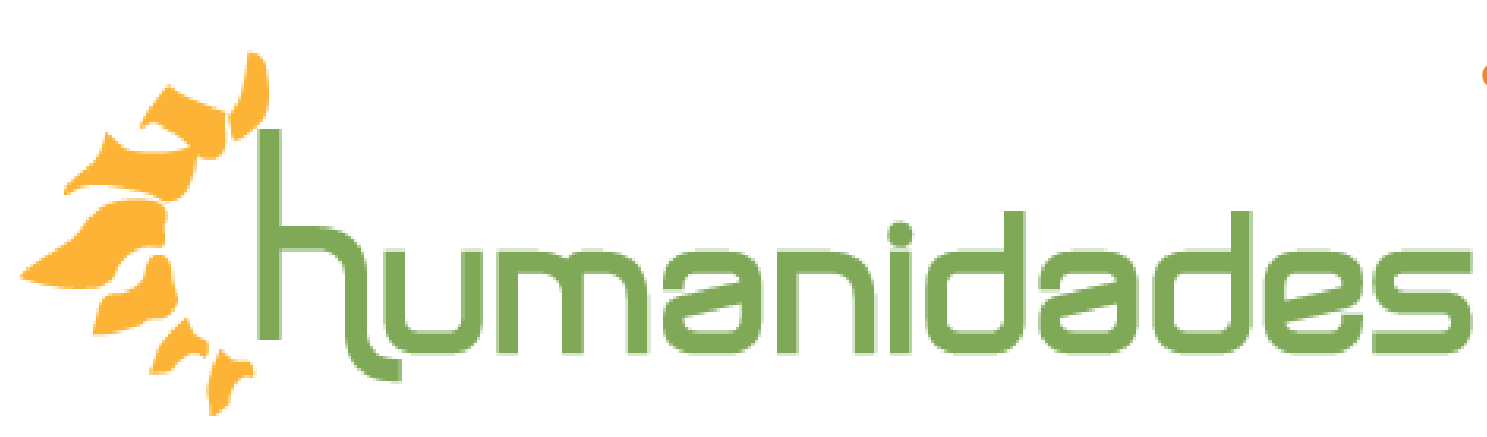

Revista de la Escuela de Estudios Generales, Universidad de Costa Rica

Enero-junio, 2018 •Volumen 8, número 1 • EISSN 2215-3934 •pp. 25-50. Recibido: 15-Septiembre-2017 Aceptado:16-Diciembre-2017

\title{
La teoría de la obra de arte total como categoría formal en el primer Romanticismo alemán
}

DOI: http://dx.doi.org/10.15517/h.v8i1.31464

Máster Iosune Aizpún Vilchez

Doctoranda en Humanidades en la Universidad Carlos III de Madrid, España. 100279492@alumnos.uc3m.es

Todos los derechos reservados. Universidad de Costa Rica. Esta revista se encuentra licenciada con Creative Commons. Reconocimiento-NoComercial-SinObraDerivada 3.0 Costa Rica. Correo electrónico: humanidades@ucr.ac.cr / Sitio web: http://revistas.ucr.ac.cr/index.php/ humanidades 


\title{
La teoría de la obra de arte total como categoría formal en el primer Romanticismo alemán
}

\section{Resumen}

Estudiaremos cómo se desarrolla en el Romanticismo temprano la teoría germinal de la obra de arte total como categoría formal, es decir, como la intención de crear una única obra donde se produzca la síntesis de todas las artes. Esta sería la culminación de un recorrido hacia la totalidad artística que comienza con la creencia en la unidad de las artes, pasa por la fusión de los géneros dentro de cada una de las disciplinas, sigue con el deseo de fusionar las distintas artes y finaliza con la voluntad de que todas estén presentes en una única obra.
Palabras claves:obra de arte total, unidad de las artes, separación de las artes, Romanticismo, teoría de los géneros

\section{The theory of the total work of art as a formal category in early German Romanticism}

\begin{abstract}
We try to demonstrate how early German Romanticism develops an embryonic theory of the total work of art as a formal category, namely, as the intention to create one single work where a synthesis of all the arts is produced. The latter would be the culmination of a way towards artistic totality that begins with the belief in the unity of the arts, goes through the fusion of genres within each art form, continues with the desire to merge the arts and ends with the will to join all of them together in one single work.
\end{abstract}

Keywords: total work of art, unity of the arts, separation of the arts, Romanticism, genre theory. 
La teoría de la obra de arte total ...

La obra de arte total, que podría definirse como el ideal romántico de síntesis superior de las artes, suele ser conocida popularmente a través del trabajo de Richard Wagner quien conformó su teoría en La obra de arte del futuro de 1849 y Ópera y drama de 1851. Al ser el compositor alemán quien dio a conocer el término gesamtkunstwerk y quien además llevó su proyecto a la práctica con la creación del ciclo El anillo del Nibelungo, no han sido pocos los autores que le han atribuido en exclusiva la autoría de esta categoría estética que sin embargo tiene sus orígenes en el primer Romanticismo alemán de la última década del siglo XVIII y principios del XIX. Al contrario de lo que declarase por ejemplo Theodor W. Adorno en Ensayo sobre Wagner (2008, p.92), donde aseguraba que su noción de gesamtkunstwerk "es sin embargo ajena a las concepciones, cincuenta años más antiguas, propiamente hablando románticas", la obra de arte total tiene precisamente sus raíces en la cosmovisión y en la estética del también conocido como Frühromantik que se conformó principalmente en torno al "Círculo de Jena".

Sin embargo esta postura resulta comprensible si consideramos que mientras la teoría de la obra de arte total es fácilmente reconocible en Wagner, ya que está recogida en esos dos ensayos que le dedicó (Wagner, 1850, 1852), no ocurre así en los primeros románticos principalmente porque estos autores no llegaron a nombrar en ningún momento el término "obra de arte total”, es decir, no llegaron a recoger su proyecto artístico bajo este nombre del mismo modo que tampoco le dedicaron un tratado icónico al modo wagneriano en el que expusieran de forma clara su ideal de síntesis de las artes. Es por ello que debemos reconstruir esa teoría germinal de la obra de arte total atendiendo, en este caso, a su aspecto puramente formal, lo que significa que dejaremos de lado todas aquellas cuestiones que lleva implícita en su trasfondo como el diagnóstico del mundo moderno como un mundo degradado, el postular el papel del arte como solución a ese mal, el anhelo de una sociedad y un arte orgánicos fijando como modelo la Grecia Clásica, la intención de unir arte y vida... para centrarnos en cómo se produce su aparición como composición concreta. Para ello debemos pensar en la obra de arte total como la culminación de un recorrido hacia la totalidad artística que se desarrolló en distintos pasos. El primero de todos es la creencia en la unidad de las artes. 
La creencia romántica en la unidad de las artes está enmarcada en el proceso de configuración de la noción occidental del arte, en cuya evolución fue muy relevante. Tal y como explica Larry Shiner (2001/2004) en su obra La invención del arte, desde la Edad Antigua hasta el siglo XVIII nuestra cultura funcionó con el denominado "antiguo sistema de las artes" en el que aparecían conglomeradas muchas disciplinas y prácticas que actualmente no consideramos arte, como las ciencias y la artesanía, y donde tampoco se habían planteado muchos de los presupuestos estéticos con los que estamos tan familiarizados. No sería hasta la llegada de la Ilustración cuando se iniciase el "moderno sistema del arte" encabezado por Las bellas artes reducidas a un mismo principio donde Charles Batteux identificaba en 1749 las disciplinas que comúnmente consideramos artes, es decir, las bellas artes (Shiner, 2001/2004). Lo hizo al dotarlas de un término y un principio común pero sin llegar a diferenciarlas entre sí, una tarea que sería acometida posteriormente por Lessing, al mostrar las diferencias entre la pintura y la poesía en su Laooconte de 1766 y por Herder en Escultura de 1778 donde estableció las diferencias entre la pintura y la escultura (Barasch, 2000).

Con las artes ya individualizadas, los románticos darán un paso más y pensarán en su unidad desde una perspectiva interna, metafísica. Creen que existen unos trasvases internos entre ellas, que comulgan misteriosamente entre sí y así plantean que las artes esconden una unidad originaria (Marchán-Fiz, 2008), o como bien interpreta Glenn W. Most, que "todas las formas de actividades artísticas constituyen las variantes de un mismo impulso creador fundamental" (2003, p.13, traducción propia). Lo que las separa sería puramente superficial en razón de las diferencias expresivas y de las "técnicas empleadas". Por eso el parentesco que se ha percibido tradicionalmente es mucho más profundo, tanto que serían una y la misma entidad creativa (Most, 2003).

Esa unidad originaria, esapulsión quepermitealosrománticospostularlaunidaddelas artes es elArte con mayúsculas. Recogiendo los avances conseguidos principalmente por Kant y por los autores del prerromanticismo alemán, los románticos hablarán de forma plena sobre el Arte en términos absolutos, como una entidad propia, como una fuerza trascendente. Con ellos la palabra "Arte" designará de forma definitiva una potencia cosmogónica, un reino metafísico privilegiado (Shiner, 2001/2004).

Este postulado de la unidad de las artes se erigirá como el presupuesto ontológico

\section{La unidad de las artes}


La teoría de la obra de arte total ...

de la obra de arte total puesto que sería el fundamento que haría posible la síntesis suprema de todas ellas. Así mismo posibilita uno de los primeros pasos previos a la obra de arte total, la fusión de los géneros artísticos, para cuya comprensión debemos situarnos en el siguiente contexto.

\section{La confrontación entre la poética romántica y la clasicista}

Cuando los primeros románticos alemanes comenzaban su andadura intelectual y artística hacia 1796, el arte, tanto en el ámbito teórico como en el práctico, se encontraba bajo los cánones del Neoclasicismo europeo del siglo XVIII que dominaría también durante parte del siglo XIX. Conocían por tanto muy bien los principios que regían la concepción clasicista del arte, una concepción que al tratar de imponerse de forma ciertamente restrictiva en este último periodo (Barasch, 1985/1991), sirvió de acicate para el surgimiento de una nueva sensibilidad que tomó como punto de partida aquellas nociones prerrománticas que ya habían mostrado un punto de disidencia con el modelo establecido.

Dentro de los parámetros de la cultura ilustrada, el Neoclasicismo suponía justamente la aplicación de los principios de la razón al ejercicio artístico. Según los eruditos de esta corriente, esos principios habrían tomado forma en las reglas del arte clásico ya que consideraban que las dictaba el sentido común y que por ello habían de ser cumplidas rigurosamente. Sin embargo estas reglas no se encuentran formuladas en la Antigüedad sino en el tratamiento que del arte clásico se hace en el Renacimiento italiano. Y es que el Neoclasicismo supone la continuidad de una corriente clasicista más longeva que comienza en la Italia del Renacimiento, toma relevo en la Francia del siglo XVII con el conocido como Clasicismo francés y desde allí se expande hacia toda Europa en el siglo XVIII (Viñas, 2002).

Los inicios de esta tradición clasicista se hallan por tanto en la labor de los críticos renacentistas quienes otorgaron una autoridad suprema a dos tratados: el Ars Poetica de Horacio y la Poética de Aristóteles. A partir de la interpretación de estas obras elaboraron una serie de reglas sobre el fin de la poesía, el decoro, las leyes de la tragedia... que acabaron constituyendo un sistema caracterizado por la exaltación de los aspectos formales en detrimento del lado subjetivo del arte (Babbitt,1910). 
Esta tendencia hacia el puro formalismo, que irá acentuándose progresivamente y caracterizará a toda la corriente, encontró su primera justificación al considerarse que las prácticas del arte barroco habían roto la unidad del estilo renacentista y se use esta directriz como medio para preservarlo. Quien recoge y conserva la teoría renacentista del arte es la Francia del siglo XVII fundando las Academias como un entorno institucional firmemente estructurado en que los académicos continuarán desarrollando además los preceptos de una renovada doctrina clásica con obras como la paradigmática Art poétique de Nicolas Boileau de 1674 (Barasch, 1985/1991).

En el siglo XVIII los principios fundamentales del Clasicismo francés se extienden al resto de países europeos y con ellos las Academias, que tendrán una influencia prácticamente absoluta al desarrollar un sistema de educación integral. Este ofrecía una formación práctica a los artistas que cubría todos los aspectos técnicos necesarios para la ejecución de las obras pero su principal objetivo era modelar los criterios que debían seguir durante el proceso creativo y que estaban determinados por lo que la Academia consideraba que eran el "buen arte" y el "buen gusto" (Barasch, 1985/1991). Todo lo que no encajase con esa doctrina establecida sería rechazado. Lo que pretendía asegurar este control era la consecución de una unidad de estilo, el estilo Neoclásico, que encarnaría el ideal de belleza y verdad universal. Precisamente la necesidad de evitar que esa belleza universal resultase demasiado abstracta provocó que se formulase un número cada vez mayor de reglas para concretar hasta los más mínimos aspectos creativos (Viñas, 2002) lo que generó un canon definitivo que a pesar de resultar muy útil por ser fácilmente reproducible, acabó siendo completamente restrictivo dando lugar a una producción muy uniforme (Portús, 2013).

La sensibilidad de los primeros románticos alemanes concibe el arte de una forma radicalmente distinta, su punto de partida es tan diferente que al desarrollarla se encontrarán en una oposición permanente a cada uno de los principios de la tradición clasicista. El arte ocupará un nuevo lugar, será su propio fundamento ya que lo entienden como una actividad libre en todos sus aspectos, como una creación original e individual que no puede estar sujeta a prescripciones. El artista, consciente de su autonomía respecto la razón y las normas, se guiará ahora por la inspiración (Argullol, 2008). 
La teoría de la obra de arte total ...

De este modo se posicionan en primer lugar contra el principio de mimesis, es decir, contra la premisa aristotélica de que el ser humano imita por instinto la realidad externa frente al cual defienden el principio de expresión, expresión de la subjetividad de cada artista que se muestra hacia el exterior por medio de la imaginación, revalorizando así esta facultad en contra de la forma en que el clasicismo la mantenía sometida a la razón (Argullol, 2008).

Sin embargo en cierta manera sí mantienen el principio de imitación: el objeto de mimesis de los clasicistas era la naturaleza, específicamente la naturaleza bella, pues interpretaban que no había que imitarla en su totalidad sino eliminar lo desagradable para idealizarla (Babbitt, 1910). Los románticos también creerán en la imitación de la naturaleza pero entendida no como objeto externo sino como fuerza productora. Esta idea implica que el artista al crear no debe situarse frente a la naturaleza, como en la imitación clasicista, sino que debe reproducir la fuerza original que actúa en ella dándose así la imitación a un nivel interno (Tollinchi, 1989).

Como consecuencia lógica los románticos tampoco cumplirán con la segunda vertiente en que se manifestaba el principio de mimesis: la imitación de los modelos clásicos. Y es que frente a la posibilidad de no saber plasmar adecuadamente la naturaleza bella, los clasicistas imitaron a aquellos que sí sabían hacerlo, los clásicos (Babbitt, 1910). Esta prescripción se basaba en un principio aún más importante: la creencia de que el arte había alcanzado su máxima perfección en el arte antiguo, que se había llegado a un estado de non plus ultra y que por ello solo cabía imitarlo literalmente para preservarlo (Viñas, 2002).

Semejante convicción será combatida por los románticos con la defensa de la originalidad. También ellos tendrán como gran referencia al mundo y al arte antiguos pero como sostenía Friedrich Schlegel, para recobrar su espíritu creativo no para copiar sus formas porque a diferencia de los clasicistas, los románticos creían que su tiempo tenía derecho a un arte y a una estética propios (Martínez, 1992)

Comprobamos entonces cómo estas dos corrientes entienden el arte de una forma completamente distinta, cómo el Romanticismo presenta una poética nueva que supone un cambio que de hecho marca el tránsito hacia el arte moderno. Ese gran cambio se origina precisamente en el reconocimiento del Arte con mayúsculas que les hace ser conscientes de estar ante 
una dimensión nueva llena de potencialidades, un arma poderosísima que el clasicismo estaría desaprovechando al someter el impulso creativo. Esa conciencia les llevará a emprender el camino contrario, el camino hacia la totalidad artística que continúa con uno de los asuntos más controvertidos para ambas poéticas.

\section{La teoría de los géneros artísticos}

La cuestión de los géneros tiene su origen en la teoría de la literatura ya que proviene de la Poética de Aristóteles quien diferenciaba tres géneros literarios: épico, lírico y dramático, cada uno con sus correspondientes subclases. La idea de género artístico supone que dentro de cada arte hay diferentes tipos de expresión según un carácter y unas finalidades que son propios de cada uno y que los distinguen entre sí (Hernández-Pacheco, 1998). Estos los vinculan a un tono y una forma determinados de modo que no se eligen las mismas palabras, la misma métrica o el mismo ritmo para una comedia que para una elegía puesto que cada género tiene adjudicadas unas reglas distintas para conseguir el efecto al que está destinado (Barasch, 1985/1991).

Este tipo de clasificaciones, que también llevó a cabo la retórica clásica, fue recibida con gran entusiasmo por la tradición clasicista que partiendo de esta base completó la elaboración de la teoría de los géneros. Esta se convirtió en una doctrina fundamental sobre todo a partir del advenimiento de la época ilustrada (Barasch, 1985/1991). De este modo, al completarse la diferenciación de los géneros se impuso la separación tácita entre ellos y se definieron claramente las reglas que eran propias para su elaboración, unas reglas que definían todo lo relativo a contenido, estilo y disposición de elementos, como por ejemplo la regla de las tres unidades dramáticas. Toda obra que perteneciera a un género determinado debía cumplir con rigurosidad estas leyes pues de lo contrario no realizaría la esencia del género en cuestión y resultaría fallida. El depender de esas normas tenía otra consecuencia más y es que no se admitían géneros nuevos ni híbridos siendo estos condenados u obviados (Viñas, 2002). Vemos entonces cómo el clasicismo defendía que los géneros son absolutamente inalterables imponiendo así un estatismo férreo en torno a ellos.

En el ámbito de las artes plásticas la clasificación por géneros comenzó con la teoría de los modos pictóricos propuesta por Nicolás Poussin, quien se inspiró en la teoría musical de la Antigua Grecia. 
La teoría de la obra de arte total ...

No obstante esta idea, que se desarrollaría también fuera del ámbito de la Academia, no adquirió relevancia hasta 1667 cuando en las Conférences de ese año André Félibien presentase no solo la enumeración de los géneros pictóricos sino su total jerarquización según la dignidad de su temática (Barasch, 1985/1991).

El Romanticismo se opondrá a esta visión estática de los géneros y será también la teoría de la literatura el ámbito desde donde comiencen a configurar su posición. La toman desde la segunda vertiente que tiene el establecimiento de los géneros y es que estos no solo sirven para dirigir al artista sino que también son el criterio que usa el receptor para enjuiciar el producto final: son esenciales para la crítica. Desde aquí comienzan a romper con la noción clásica de los géneros por el juicio que les merece la novela Los años de aprendizaje de Wilhelm Meister de Goethe.

La publicación de esta obra entre 1795 y 1796, coincidiendo temporalmente con la conformación del Círculo de Jena, tuvo un impacto definitivo en la forma en que estos autores iban a concebir la novela (Tymms, 1955) al considerar que rompía con su situación: era el único gran género poético que al no tener una genealogía histórica digna había sido menospreciado por la preceptiva clásica, la cual o la condenaba completamente o consideraba con muchas reservas que podría ser útil para la enseñanza moral (Montandon, 1999). Será principalmente Friedrich Schlegel quien haga de portavoz de esta postura y en su reseña Sobre el Meister de Goethe publicada en la revista Athenaeum en 1798 dictamine que:

Juzgar este libro completamente nuevo y único, que solo se comprende por sí mismo, según un concepto de género compuesto y surgido de la costumbre y la fe, de experiencias azarosas y exigencias arbitrarias; sería como si un niño quisiera coger con la mano la luna y las estrellas y meterlas en una cajita (1960, pp.334-335, traducción propia).

Y es que según la crítica tradicional la novela de Goethe resultaría fallida al no encajar con los géneros convencionales. Ante esta postura, los románticos vuelven a la obra y de nuevo tienen la certeza de que no puede estar mal, dándose entonces cuenta de que es en realidad la crítica clásica la que no es correcta porque juzga las obras según un modelo exterior cuando hay obras, como en este caso, que rompen moldes, que son su propio parámetro 
Por eso los románticos defenderán una nueva forma de crítica en que lo más importante sea lo singular de cada obra, lo que la hace única o como designa Schlegel, lo "característico" que la diferencia de las demás. Al ser única, la obra se regirá por unos principios que le son propios, de modo que la tarea del crítico será ahora averiguar cuáles son y determinar si satisface o no ese ideal. Para ello se exigirá que el crítico demuestre tener sensibilidad artística (Viñas, 2002) pues de lo contrario no podrá poner de relieve aquello que en la creación de la obra se realiza de forma inconsciente. Así la crítica se convierte en un momento inmanente de la propia obra; es una crítica artística (Martínez, 1992).

Pero lo que realmente falla en la crítica tradicional para los románticos es el postulado sobre el que se sustenta: que los clasicistas considerasen que el arte había alcanzado la perfección con el arte clásico suponía que no esperaban nada más del arte, que no creían que hubiera nada mejor por venir y justamente por ello se dedicaron a establecer los géneros con sus correspondientes normas como método para preservar lo ya obtenido. En cambio los románticos proponen un modelo de crítica que precisamente permite la apertura a lo nuevo, con el que no se cierran al futuro porque creen que el arte todavía puede dar grandes frutos. Recogerán esta idea bajo el principio de que el arte es "progresivo", es decir, que se desarrolla hacia el infinito, que se encuentra en continuo devenir, siendo esta la causa de que siempre surjan obras que rompen los parámetros anteriores. La consecuencia directa de este planteamiento es que no se puede establecer un estatismo absoluto en torno a la creación artística encorsetándola en géneros cerrados puesto que si todo está sujeto a cambio, los estándares de una época pasada no pueden servir para otra futura (Viñas, 2002). Es por este motivo por el que Friedrich Schlegel dictaminará que "en su rigurosa pureza, todos los modos poéticos clásicos son hoy ridículos" (Arnaldo, 1994, p.74 ).

De este modo rompen los románticos con la teoría clásica de los géneros. Sin llegar a abandonarlos, anulan su dimensión normativa porque proponen transgredir sus límites, superar su rigurosa separación para interrelacionarlos con fluidez. Mezclarán géneros distintos, producirán otros nuevos como el "fragmento", aplicarán las normas de uno a otro e intercambiarán temas y formas (Marchán-Fiz, 2008). Así, cada cual comenzará por diluir los géneros que encuentra dentro de su propia disciplina.

Friedrich Schlegel y Novalis aspiran a una literatura en la que acometer 
La teoría de la obra de arte total ...

mezclas y asociaciones libres nunca antes vistas (Schefer, 2011) y la concentran en su idea de novela, donde proyectarán su deseo de totalidad artística al ver en ella la posibilidad de unir todos los géneros literarios (Tollinchi, 1989). En las adaptaciones prácticas de ese ideal, sus respectivas obras Lucinda y Enrique de Ofterdingen, incorporan en su prosa fragmentos líricos y teatrales, dejarán traslucir un trasfondo filosófico y aparecerán partes semejantes a un tratado pedagógico o a un manifiesto político (Hernández-Pacheco, 1995).

En el ámbito de las artes plásticas, como bien señala Javier Arnaldo (1990), los pintores románticos desarticularán la jerarquía académica al revalorizar los géneros menores que como la naturaleza muerta o el retrato habían sido menospreciados frente a temas considerados de mayor dignidad como la pintura histórica o mitológica. Uno de esos géneros, el paisaje será además encumbrado a lo más alto desbancando a la pintura de figuras. Igualmente procederán a mezclar los géneros: el retrato noble integrará elementos de la imaginería popular, se desdibujarán los límites entre la veduta y el paisaje ideal y las artes decorativas podrán generar imágenes simbólicas (Arnaldo, 1990). Encontraremos así grandes obras situadas entre dos géneros, como en la pintura de Caspar David Friedrich, especialista en dotar a sus paisajes de un intenso carácter religioso (Schefer, 2011).

Sin embargo la razón última por la que el Romanticismo temprano puede permitirse mezclar los géneros no es otra que la unidad del arte, ya que si el arte es una entidad propia, en ella "se conectan recíprocamente y se unifican" todas las "formas de exposición". Tal y como lo expresa Walter Benjamin (1974/1988) en El concepto de critica de arte en el Romanticismo alemán, "la idea romántica de la unidad del arte anida, por consiguiente, en la idea de un continuum de las formas. Así, por ejemplo, la tragedia enlazaría para el espectador, sin solución de continuidad, con el soneto" (p.129).

No obstante, esta unión de los géneros no era más que el inicio del camino hacia la totalidad artística y esto es lo que hemos estado tratando hasta ahora. La cuestión crucial será sin embargo conocer cómo se produce el salto de una teoría de los géneros clásica a la separación neta de las artes, y de forma más importante aún, cómo en oposición a ella, al ser coherentes con su concepción artística, los primeros románticos apostarán por romper también esas barreras y postulen la unión de las artes, descubriéndose así la teoría germinal de la obra de arte total. 
Necesitaremos comenzar entonces por saber quiénes fueron los responsables de la separación de las artes.

\section{La separación neta de las artes en la tradición clasicista y la unión de las artes en el Romanticismo}

A primera vista podríamos señalar a la corriente clasicista en general y estaríamos en lo cierto pero no es una cuestión tan sencilla. Lo primero que debemos tener en cuenta es que el estilo clasicista es un estilo que de por sí separa las artes a nivel práctico. Sus manifestaciones artísticas se caracterizan por emplear formas de expresión "puras", aquellas que permanecen dentro del ámbito de cada arte individual, con una clara oposición al uso de recursos de diferentes disciplinas en una sola obra. Recordemos que uno de los motivos por los que se consolidó la corriente clasicista fue su animadversión a la integración de las artes practicada por el Barroco. De hecho, este gusto por una estética "unilateral" afectó incluso al teatro que, consistiendo tradicionalmente en una combinación de muchos medios expresivos diferentes se vio afectado desde el siglo XVIII por la reducción de medios propugnada por la principal corriente dramática clasicista que consideraba prioritario ensalzar la palabra hablada como componente esencial de este arte (Berghaus, 2012).

Incidimos en que se trata de una separación de las artes a nivel práctico porque la justificación teórica de dicha separación llegó relativamente tarde, avanzado ya el periodo neoclásico. La razón la encontramos en que la corriente clasicista es como hemos visto muy longeva y tiene sus inicios en el Renacimiento italiano cuando aún estaba vigente el antiguo sistema del arte lo que implica que en el proceso de consolidación de sus principios no se contaba con la madurez teórica suficiente para formular la separación de las disciplinas artísticas puesto que aún no se habían dado los pasos necesarios para ello. Resulta llamativo porque supone que mientras se defendía una estricta separación de los géneros, no se contaba aún con una teoría sobre una separación de las artes que sin embargo se practicaba. Es comprensible si tenemos en cuenta que la teoría de los géneros es fácilmente deducible de la tradición humanística, pero no así la separación de las artes, que será fruto de la reflexión artística moderna. 
La teoría de la obra de arte total ...

Los responsables a nivel teórico de dicha separación serán los mismos autores que procedieron a "diferenciar" las artes, Lessing y Herder, quienes iniciaron una tendencia de investigación para descubrir y manifestar la naturaleza única de cada arte. Ciertamente esta tendencia puede conducir a ver las artes como órdenes completamente distintos: Lessing había demostrado que las artes difieren en el medio material lo que las situaba en dos dimensiones distintas, la del espacio y la del tiempo, y eso además le había llevado aún más lejos, a plantear que tampoco imitan el mismo tipo de objeto. Pero es que incluso dentro de un mismo grupo como es el de las artes plásticas, que son artes espaciales e imitan el mismo tipo de objeto, los cuerpos, se vuelve a abrir una brecha con las reflexiones de Herder, ya que al apelar a distintos sentidos ni siquiera son percibidas de la misma manera por el espectador. La distancia entre arte y arte, cada vez más pronunciada, puede llegar a verse como insalvable (Barasch, 2000) y así ocurre con estos autores: el plantear que las artes tienen unos atributos propios intransferibles les conduce a la conclusión de que ni se puede ni se deben mezclar las artes. El dictamen de Herder lo encontramos en el propio tratado Escultura:

Se trata, por tanto, de unos límites ordenados por la propia naturaleza, y no del producto de una convención; así pues, ninguna convención puede alterarlos sin que la naturaleza se tome su revancha. Un arte sonoro que pretenda pintar, una pintura que quiera sonar o esculpir en piedra, o una escultura servirse de color no son sino anormalidades con independencia de sus efectos eventualmente equivocados (1778/2006, p.55).

Pero fue Lessing el primero en reivindicar la separación de las artes porque en el Laocoonte da un paso más y afirma que si cada arte imita de manera diferente al estar limitada por los recursos que le son propios, solo debe imitar los objetos y temas que son adecuados para la naturaleza de su medio. Es decir, hay unos límites naturales en las artes que no deben traspasarse. Con esta idea se dirige principalmente a los poetas para que "se abstengan de enriquecer sus obras sirviéndose de lo que la pintura emplea por necesidad" (1766/1985, p.123). Así pretendía evitar que se practicase la emulación entre artes diferentes o se creasen híbridos artísticos que solo podían dar lugar a fracasos estéticos (Most, 2003).

Su postulado sobre la separación de las artes caló en la opinión intelectual y artística ya que Lessing era uno de los escritores alemanes más respetados y venerados de su época y su Laocoonte, recibido con mucha expectación, fue tan exitoso que frenó la moda de la poesía descriptiva que arrasaba en la literatura alemana (Kristeller, 1952). 
Sin embargo, la causa profunda de esta total aceptación la encontramos en que este principio encajaba a la perfección con la separación de las artes que ya se practicaba porque debemos caer en la cuenta de que la aplicación de los géneros clásicos tal y como estaban establecidos suponía un circuito cerrado de lo que se podía y no podía hacer en la creación artística, y en esa estructura fija no había espacio para mezclar las artes, no se dejaron resquicios ni "vacíos legales" para ello. Es decir, la determinación de los géneros dentro de cada arte suponía una separación de las artes de facto. Pensemos entonces cómo consecuentemente en el caso contrario, la idea romántica de unión de los géneros permitiría la libertad de movimiento suficiente como para posibilitar la unión de las artes.

No obstante, la justificación teórica de esta separación supuso un cambio y es que los autores doctrinarios, empezando por Lessing, usaron esta base para imponer la estricta separación de las disciplinas artísticas prohibiendo cualquier traspaso de sus fronteras (Munro, 1949) bajo la defensa de que las artes solo comparten una afinidad "ideal" y que su unión supondría la decadencia del arte (Arnaldo, 1990). Esta tendencia represiva tuvo su continuación en la generación siguiente, concretamente en la Alemania del llamado Clasicismo de Weimar y este será justo el contexto en que se encuentren los primeros románticos al desarrollar su proyecto, siendo dos autores en particular, Carl Ludwig Fernow y Goethe, ya en su etapa de madurez, con quienes mantengan una hostilidad abierta como bien relata Karl Konrad Polheim (1970).

Fernow, a quien veremos pronunciarse con contundencia más adelante, era uno de los teóricos del arte más destacados del clasicismo tardío. Ya en la revista que dirigía, El nuevo Mercurio alemán, había plasmado su postura en torno a la unión de las artes al tratar el tema de los límites de la pintura dramática en 1797 (Polheim, 1970), una postura que coincidía por completo con la mantenida por Goethe en ese mismo año en una carta dirigida a Friedrich Schiller:

El artista debería ahora resistirse con todas sus fuerzas a esas tendencias realmente pueriles, bárbaras, de mal gusto, debería separar cada obra de arte de la otra por impenetrables círculos mágicos, mantener cada obra en su especificidad y cualidades propias tal como lo hicieron los antiguos convirtiéndose y permaneciendo, así como tan grandes artistas (Schiller y Goethe, 1881, p.344, traducción propia). 
La teoría de la obra de arte total ...

Un año más tarde, en 1798, Goethe fundaría junto a Schiller la revista Los propileos, que se convertiría en la publicación programática del Clasicismo alemán, y en su introducción deja aún de forma más clara su posición:

Uno de los principales rasgos de la decadencia del arte es la mezcla de sus diversas modalidades. Las propias artes, así como sus modos, están emparentadas entre sí, tienen cierta tendencia a unirse, e incluso a perderse unas en otras; pero precisamente el deber, el mérito, la dignidad del verdadero artista consisten en separar de las otras el arte en que trabaja, ajustar cada arte y modalidad artística a sí misma y aislarla todo lo que sea posible (pp. XXIV-XXV, traducción propia).

Podríamos resumir el sentir de los románticos ante esta tajante determinación con una cita de lo que August Wilhem Schlegel pronunció en sus Conferencias sobre arte dramático y Literatura en 1808 y que se puede aplicar tanto a la cuestión de los géneros como a la unión de las artes: "El arte y la poesía antiguos separaban rigurosamente lo desigual; lo romántico se complace en mezclas indisolubles" (1817, vol.3, p.14, traducción propia). Pero sin adelantarnos más veamos cómo reaccionaron en ese mismo año de 1798 tres de estos autores a las declaraciones de Goethe.

Por un lado, Ludwig Tieck impregnaría toda su novela Franz Sternbald con diversas ideas sobre el arte entre las que podemos encontrar: "Creo por eso que la música, la poesía y la pintura a menudo se dan la mano, que ciertamente pueden alinearse hacia una y la misma cosa en su camino" (1843, p.302, traducción propia). Por su parte, Novalis expondría que "La plástica, la música y la poesía se comportan como la épica, la lírica y el drama. Son elementos inseparables que aparecen conjuntamente en cada esencia artística libre y solo se unifican según su naturaleza en proporciones diferentes" (1840, p.323, traducción propia).

Estas enunciaciones aún no son lo suficientemente claras como para ver en ellas una declaración explícita de la pretensión romántica de unir las artes, aunque en su caso Novalis establecería un paralelismo entre los géneros de la poesía y las tres artes principales. Donde se encontraría la manifestación romántica de ese deseo es en un escrito de Friedrich Schlegel de ese mismo año 1798 publicado en la recién fundada revista del Romanticismo temprano Athenaeum: el célebre fragmento 116. 
La poesía romántica es una poesía universal progresiva. Su designio no consiste únicamente en volver a unir todos los géneros disgregados de la poesía y en poner en contacto a la poesía con la filosofía y la retórica. Quiere y debe mezclar poesía y prosa, genialidad y crítica, poesía del arte y poesía de la naturaleza, fundirlas, hacer viva y sociable la poesía y poéticas, la vida y la sociedad [...] (Arnaldo, 1994, p.137).

A primera vista Schlegel estaría hablando de volver a unir todos los géneros de la poesía, es decir, de la literatura, de modo que solo estaría haciendo referencia a un único arte y a la mezcla de géneros que ya hemos tratado. Sin embargo, el realizar un ejercicio de interpretación nos permitirá descubrir en este mismo fragmento la teoría de la unión de las artes si entendemos que cuando Schlegel usa el término "poesía" lo hace en realidad para referirse al "Arte" en general.

Esta suposición encuentra su fundamento en la siguiente cuestión: como explicamos los románticos llegaron al convencimiento de la existencia del Arte como una entidad propia. Este concepto no quedaría firmemente establecido hasta 1830 (Shiner, 2001/2004) lo que significa que lo que muestran los primeros románticos en sus escritos es el proceso de descubrimiento y consolidación de la nueva noción. Además, el descubrimiento tomaba como punto de partida las analogías entre las artes, que se tomaron en un sentido literal antes de pasar a una perspectiva metafísica. Así, del mismo modo en que Philipp Otto Runge consideraba que era la música la que actuaba como un eje común y unificador, siendo una “armonía y tranquilidad en las otras tres artes" (1840, p.43, traducción propia), la mayor parte de los primeros románticos como Novalis, Friedrich y August Wilhelm Schlegel creían que era la poesía aquello que estaba presente en todas ellas.

De este modo Friedrich Schlegel apuntaría en 1800 en Conversación sobre la poesía que: "los misterios más íntimos de todas las artes y ciencias son propiedad de la poesía. De ahí surge todo, y hacia allí todo debe confluir" (1800/2005, p.71) añadiendo en 1803 que "La poesía unifica todo arte [...] Poesía es música, pintura en palabras" (1958, p.10, traducción propia). Pero aún es más claro su hermano August Wilhelm cuando anticipa que "es la poesía, como se ha demostrado muchas veces, una especie de punto medio común de las artes, al que regresan y del que parten de nuevo" (1884, p.6, traducción propia). 
La teoría de la obra de arte total ...

Compartimos entonces la posición mantenida por autores como Walter Benjamin (1974/1988) o Frederick Beiser (2003) cuando defienden que los primeros románticos no se restringirían al ámbito puramente literario al hablar de "poesía". De esta manera, al hacer la sustitución de términos, encontramos en el fragmento 116 la afirmación de que "el arte romántico es un arte universal y progresivo" y que parte de su designio es "volver a unir todos los géneros disgregados del arte", es decir, las distintas artes. Igualmente podemos entender desde esta nueva perspectiva aquellos comentarios sobre lo ridículo de mantener los géneros en su rígida compartimentación aplicándolo ahora a la estricta separación de las artes.

Sería esta la forma en que dentro de la teoría de la unión de los géneros de cada arte el Romanticismo temprano desvelaría además su teoría de la unión de las distintas artes, una pretensión que parecía ser muy clara en la época sobre todo para sus opositores que como Fernow, saldría al paso en sus Estudios romanos de 1806 para calificar este afán romántico de "inútil palabrería de esos fantasiosos que gustan de revolver unas con otras y todas las artes" (p.X, traducción propia). Una reacción lógica si tenemos en cuenta algunas expresiones románticas como esta de 1802 en la que el propio Friedrich Schlegel expresaba que "El sentido arquitectónico-plástico-musical-pintoresco constituye lo esencial de lo romántico" (como se citó en Arnaldo, 1990, p.124).

Sin embargo, a nuestro parecer hay un fragmento que no siendo tan célebre como el mencionado 116 aún mostraría de forma más clara la intención romántica de unir las artes y vendría de la mano de August Wilhelm Schlegel quien también en el Athenaeum y en fechas cercanas llamaba a:

Nutrir las artes unas con otras y encontrar puentes entre unas y otras. Las columnas puedenquizáconvertirseenpinturas, [...]laspinturas enpoemas, los poemas en músicas; ¿y quién sabe? una majestuosa música sacra se elevaría de repente en el aire como un templo (1960, pp.49-50, traducción propia).

En este caso sí que vemos claramente la llamada a transgredir las fronteras entre las artes, a interrelacionarlas, y en este sentido podemos observar una serie de prácticas que obedecerían a este imperativo de anular los límites que se habían establecido entre las disciplinas. Pero si bien este paso es indispensable y muy próximo a la obra de arte total, aún no contiene exactamente la formulación de esta entendida como gesamtkunstwerk es decir, como el deseo de crear una única 
obraenquetodaslasdisciplinasartísticasoalmenoslastresprincipalesesténpresentes.

\section{La interrelación de las artes y sus corresponden- cias}

Lo que encontramos en este paso inmediatamente previo es justamente la respuesta a esa llamada conjunta de la cual August Wilhelm Schlegel es portavoz y que tendría dos movimientos directamente relacionados: "nutrir las artes unas con otras" y "encontrar sus puentes".

El primero tiene su reflejo práctico cuando los románticos potencian en el ámbito de su propia disciplina la presencia del carácter de un arte distinto. El ejemplo mayoritario lo encontramos en el caso de la literatura, en la que los escritores tratarán de evidenciar la presencia de la música: Josef von Eichendorff o Clemens Brentano, por ejemplo, en su Pequeña serenata nocturna, emplearon recurrentemente la onomatopeya, la asonancia y la aliteración por ser justamente los recursos sonoro-musicales más claros de que dispone el lenguaje poético (Most, 2003). Ludwig Tieck daba un paso más al querer convertir su narración poética La bella Magelone en una composición musical recurriendo también a efectos como la onomatopeya pero sobre todo dotando a esta obra poética de fluidez musical, algo que según August Wilhelm Schlegel consiguió. También en la comedia satírica El mundo al revés trató de crear una "sinfonía de palabras" como apertura de la obra en la que asigna partes del diálogo a distintos instrumentos como el primer violín, cuyo discurso trata además de la interrelación de las artes (Tymms, 1955) al comentar: “¿Cómo? ¿No debería permitirse, ni ser posible, pensar con sonidos y hacer música con palabras y pensamientos? [...] la mayoría de las cosas en el mundo lindan entre sí mucho más de lo que piensas" (Tieck, 1828, vol.5, pp.286287, traducción propia). Dentro del ámbito de la literatura continúa también Novalis pero no solo para enriquecerla con la música sino también con la pintura a través de numerosas referencias al color, especialmente el azul, al que dota de un significado especial (Miguel-Pueyo, 2009).

El segundo movimiento conlleva la búsqueda de los puentes entre las disciplinas artísticas, una labor que implica una investigación interna sobre las posibles correspondencias entre las artes y que toma forma, entre otros casos, en el interés ha-

cia la sinestesia. Este fenómeno, en que el estímulo sensorial de un único sentido 
La teoría de la obra de arte total ...

despierta junto a él una sensación de otro sentido distinto, es recogido por Tieck en El príncipe Zerbino de 1799 donde relata que "color, fragancia, canto, se proclaman como hermanos" (1828, vol.10, p.251, traducción propia) o también por E.T.A. Hoffmann quien trataba de explicar que:

Especialmente cuando he escuchado mucha música, tiene lugar en mí una confusión de colores, sonidos y aromas. Es como si todos ellos surgieran misteriosamente juntos del mismo rayo de luz y luego se unieran para formar un maravilloso concierto (1841, p.581, traducción propia).

Este último autor habría mostrado interés particularmente por la correspondencia entre los colores y los sonidos en un apunte titulado El club poético-musical de Kreisler donde asignaba a ciertas cualidades de las notas el nombre de colores (Babbitt, 1910). Del mism o modo August Wilhelm Schlegel se habría anticipado a la audition colorée practicada por los simbolistas franceses al asociar cada una de las vocales con determinados colores (Tymms, 1955). Pero sería el pintor Philipp Otto Runge quien más habría investigado sobre la naturaleza del color en su Esfera de colores de 1810 usándola como base, aunque de forma incipiente, para establecer las correspondencias entre el orden cromático y el sistema de notación musical asimilando las gamas cromáticas más claras a las escalas musicales más altas y las más oscuras a las escalas más graves. Con estas investigaciones habría pretendido llevar a cabo la musicalidad de las artes plásticas (Arnaldo,1994).

Otra de las formas en que los románticos investigaron las correspondencias entre las artes fue el motivo del arabesco. Procedente del ámbito de las artes visuales, donde se materializaba como un tipo de ornamentación, el arabesco es para los románticos una abstracción. Su carácter como despliegue libre y orgánico que se desarrolla en múltiples ramificaciones entre las cuales siempre se mantiene una relación de totalidad que manifiesta una unidad, lo convertiría en una especie de representación del propio lenguaje artístico, manifestándose por ello no solo en la pintura sino también en la música y en la poesía (Arnaldo, 1990). Friedrich Schlegel lo denominaría "la forma más antigua y original de la fantasía" (Arnaldo, 1994, p.203), una forma que acabaría estableciendo un nexo de unión entre las artes que permitiría a Novalis afirmar que "la auténtica música visible son los arabescos, las muestras, los ornamentos" (Arnaldo, 1994, p.162). 
Se produce cuando los primeros románticos, después de haber trabajado la unión de las artes desde una perspectiva interna, lo hagan desde otra externa al redirigir su atención hacia el efecto producido sobre el espectador ya que se darán cuenta de que este es mucho mayor cuando varias artes se presentan juntas. En 1798 Novalis escribía en Poeticismos:

Las obras de arte plástico nunca deberían ser vistas sin música - y, a la inversa, las piezas musicales solo habrían de escucharse en salas bellamente decoradas. Las obras de arte poético, por otro lado, no han de prescindir ni de uno ni de otro arte para su disfrute. En ello radica que la poesía opere de forma tan extraordinaria en los teatros hermosos o en las iglesias elegantes (Arnaldo, 1994, p.108).

En esta afirmación se muestra claramente la conciencia del poder conjunto de las artes, esa "forma extraordinaria de operar" que los románticos reconocerán rápidamente $\mathrm{y}$ de forma paradigmática en uno de sus grandes referentes: el drama en la Antigüedad. Será Schelling quien en Filosofía del arte de 1802 nos ofrezca la formulación más explícita de la obra de arte total de todo el Romanticismo temprano. Tras exponer todo su sistema de clasificación de las artes, presenta justo al final y brevemente la demanda de la combinación de todas ellas en una única forma artística: la ópera moderna.

Después de haber alcanzado en el drama la totalidad suprema en sus dos formas, el arte discursivo solo puede aspirar a retornar al arte figurativo, pero no a seguir desarrollándose. La poesía retorna a la música en el canto, a la pintura en el baile (en parte en la medida en que es ballet, en parte en cuanto que es pantomima), a la verdadera plástica en el arte dramático, que es una plástica viviente. [...] Quiero observar aún que la composición más perfecta de todas las artes, la reunión de poesía y música por el canto, de poesía y pintura por la danza, es sintetizada a su vez en la manifestación teatral, más compleja que fue el drama en la antigüedad, de la que solo nos ha quedado una caricatura, la ópera, que con un estilo más elevado y noble por parte de la poesía así como de las demás artes concurrentes, podría conducirnos de nuevo a la representación del antiguo drama combinado con música y canto (Schelling, 1802/2006, p.492).

La elaboración de un esquema de síntesis de todas las artes, la proposición de la ópera como composición idónea para dicha síntesis, la crítica de la decadencia de esta en su tiempo frente a la perfección del teatro griego, son elementos que estarán presentes en la teoría de Wagner de modo que aún sin ser mencionada
6. El paso definitivo
hacia la obra de arte total 
La teoría de la obra de arte total ...

podemos ver que la gesamtkunstwerk toma forma ya en Schelling (Most, 2003). Y esto ocurre por la referencia al poder del drama, un poder sobre el que volvería a incidir años más tarde August Wilhelm Schlegel en sus Conferencias sobre arte dramático y literatura donde lo define como el arte "donde muchas artes se combinan para producir un efecto mágico" (1817, vol.1, p.54, traducción propia). De nuevo aparece la referencia al efecto conjunto de las artes, un efecto final que según Schlegel es a su vez producto de una intrincada acumulación de efectos entre los que figuran desde la integración del individuo en una comunidad de espectadores, con la que interactúa al ser sus emociones conmovidas simultáneamente por acción del diálogo, hasta la estimulación de todos sus sentidos por la decoración, la iluminación y la música, factores que al combinarse no solo provocan sino que aumentan la ilusión dramática (Burwick, 1991). Schlegel, que vuelve a tomar de ejemplo al drama antiguo, tampoco llega a mencionar el término gesamtkunstwerk pero sin embargo este sí aparece en 1827 en los escritos del filósofo romántico K.F.E. Trahndorff.

De manera contraria a la creencia popular, no fue Wagner quien acuñó el término gesamtkunstwerk sino este último autor en su obra Estética o teoría de la concepción del mundo y el arte donde lo utiliza para explicar cómo las cuatro artes principales, el arte del sonido de la palabra, la música, la mímica y la danza, tienen implícita la capacidad de unirse para conformar un único espectáculo siguiendo una aspiración fundamental hacia la gesamtkunstwerke que es común a todo dominio artístico (Trahndorff, 1827).

De esta forma llegamos, varias décadas después del apogeo del Romanticismo temprano, hasta Wagner quien al fin nos ofrecerá la formulación definitiva de la gesamtkunstwerk en cuya gestación aparece de nuevo la preocupación por el efecto sobre el público que le conduce a postular, con más firmeza si cabe, al drama antiguo como gran referente de esta forma artística superior. El compositor sigue así el camino marcado por Schelling cumpliendo de hecho su deseo de revitalización del género operístico. El propio Wagner explicaba el surgimiento de la idea en una carta abierta dirigida al músico francés Berlioz publicada en 1860:

Me preguntaba cuáles debían ser las condiciones del arte para que este pudiera inspirar al público un respeto inviolable, $\mathrm{y}$, a fin de no aventurarme demasiado en el examen de esta cuestión, fui a buscar mi punto de partida en la Grecia antigua. Allí encontré desde el principio la obra artística por excelencia, el drama, en el que la idea, por sublime, por profunda que sea, puede manifestarse con la mayor claridad y de la forma más universalmente inteligible. Hoy nos sorprende con razón que treinta mil griegos pudieran seguir con un interés constante la representación de las tragedias de Esquilo; pero si buscamos la manera por la cual se obtenían tales resultados encontramos que es por la alianza de todas las artes trabajando juntas por un mismo propósito, 
es decir, la producción de la obra artística más perfecta y la única verdadera. Ello me condujo a estudiar las relaciones de las diversas ramas del arte entre sí [...] Me di cuenta, en efecto, que allí donde una de estas artes alcanzaba sus límites infranqueables, comenzaba inmediatamente, con la más rigurosa exactitud, la esfera de acción de otra; que, consecuentemente, por la unión íntima de estas dos artes, se expresaría con la claridad más satisfactoria aquello que no podían expresar cada una de ellas por separado; que, por el contrario, toda tentativa de lograr con los medios de una de ellas lo que no podría ser logrado sino por el conjunto de ambas, debía fatalmente conducir a la oscuridad, a la confusión primero, y después a la degeneración y a la corrupción de cada arte en particular (1860, traducción propia).

Adorno, T.W. (2008). Monografias musicales. Madrid: Akal.

Argullol, R. (2008). El héroe y el único. Barcelona: Acantilado.

Arnaldo, J. (1990). Estilo y naturaleza: La obra de arte en el Romanticismo alemán. Madrid: Visor.

Arnaldo, J. (Ed.). (1994). Fragmentos para una teoría romántica del arte: Novalis, F. Schiller, F. y A.W. Schlegel, H. von Kleist, F. Hölderlin... [Antología] Madrid: Tecnos.

Babbitt, I. (1910). The new Laokoon: An essay on the confusion of the arts. Boston: HoughtonMifflin.Recuperadodehttps://archive.org/details/cu31924014190189

Barasch, M. (1991). Teorías del arte: Vol.1. De Platón a Winckelmann. (F. Salcedo trad.). Madrid: Alianza Editorial. (Obra original publicada en 1985).

Barasch, M. (2000). Theories of art: Vol. 2. From Winckelmann to Baudelaire. Nueva York: Routledge.

Beiser, F. C. (2003). The romantic imperative: The concept of early german Romanticism. Cambridge MA: Harvard University Press.

\section{Referencias}


La teoría de la obra de arte total ...

Benjamin, W. (1988). El concepto de crítica de arte en el Romanticismo alemán. (J.F. Yvars y V. Jarque, trad.). Barcelona: Península. (Obra original publicada en 1974).

Berghaus, G. (2012). The futurist conception of gesamtkunstwerk and Marinetti's total theatre. Italogramma, 4, pp. 283-302. Recuperado de http://italogramma.elte.hu/sites/default/files/cikkek/letoltheto/pdf/Italogramma_Sul\%20 fil_283-302_Berghaus.pdf

Burwick, F. (1991). Illusion and the drama: Critical theory of the Enlightenment and Romantic era. University Park Pa.: Pennsylvania State University Press.

Fernow, C.L. (1806). Römische studien. Zúrich: Gessner. Recuperado de http://www.mdz-nbn-resolving.de/urn/resolver.pl?urn=urn:nbn:de:bvb:12-bsb10258208-6

Goethe, J.W. (1798). Propyläen eine periodische schrift. Tubinga: Cotta. Recuperado de http://www.mdz-nbn-resolving.de/urn/resolver.pl?urn=urn:nbn:de:bvb:12-bsb10573925-3

Herder, J. G. (2006). Escultura: Algunas observaciones sobre la forma y la figura a partir del sueño plástico de Pigmalion. (V. Jarque, trad.). Valencia: Universitat de valencia. (Obra original publicada en 1778)

Hernández-Pacheco, J. (1995). La conciencia romántica: Con una antología de textos. Madrid: Tecnos. Recuperado de http://personal.us.es/jpacheco/Textos-PDF/La-conciencia-romantica.pdf

Hernández-Pacheco, J. (1998). El cinematógrafo, ideal romántico de arte total. El gnomo: Boletín de estudios becquerianos, (7), pp.133-144. Recuperado de http://personal.us.es/jpacheco/Textos-PDF/EL-cine.pdf

Hoffmann, E.T.A., (1841). Hoffmann's sämmtliche werke: 1776-1822. París: Baudry. Recuperado de https://hdl.handle.net/2027/nnc1.cu50327895 
Kristeller, P. O. (1952). The modern system of the arts: A study in the history of aesthetics II. Journal of the History of Ideas, 13 (1), pp.17-46. Recuperado de http://www.jstor.org/stable/2707724

Lessing, G.E. (1985). Laocoonte o sobre los límites en la pintura y la poesía. Barcelona: Orbis. (Obra original publicada en 1766).

Marchán-Fiz, S. (2008). La obra de arte total: Génesis de una categoría estético -artística y sus transformaciones. En M. M. de Argila (Ed.), Arte Moderno: Ideas y conceptos (pp. 127-165). Madrid: Fundación Mapfre.

Martínez, M. A. (1992). El camino romántico a la objetividad estética: La filosofía del joven F. Schlegel como programa del primer Romanticismo alemán. Murcia: Universidad de Murcia.

Miguel-Pueyo, C. (2009). El color del Romanticismo: En busca del arte total. New York: Peter Lang.

Montandon, A. (1999). Le roman au XVIIIe siècle en Europe. París : Presses Universitaires de France. Recuperado de http://gallica.bnf.fr/ark:/12148/bpt6k4805707k

Most, G. W. (2003). Nietzsche, Wagner et la nostalgie de l'oeuvre d'art totale. En J. Galard y J. Zugazagoitia (Eds.), L'oeuvre d'art totale (pp. 11-34). París: Gallimard y Musée du Louvre.

Munro, T. (1949). The arts and their interrelations. Nueva York: The Liberal Arts Press. Recuperado de https://archive.org/details/artsandtheirinte030350mbp

Novalis. (1840). Novalis schriften. París: Baudry. Recuperado de https://hdl.handle.net/2027/hvd.hwspe1

Polheim, K. (1970). Zur romantischen einheit der künste. [La unidad romántica de las artes] En Bildende kunst und literatur: Beiträge zum problem ihrer wechselbeziehungen im neunzehnten jahrhundert (pp. 157-178). Frankfurt am Main: Klostermann. 
La teoría de la obra de arte total ...

Portús, J. (2013). La imagen barroca. En P. Aullón de Haro (Ed.), Barroco (pp.299348). Madrid: Verbum.

Runge, P.O. (1840). Hinterlassene schriften (vol.1). Hamburgo: F. Perthes. Recuperado de https://hdl.handle.net/2027/umn.31951p01104142o

Schefer, O. (2011). Variations on totality: Romanticism and the total work of art. En A. Finger y D. Follett (Eds.), The aesthetics of the total artwork: On borders and fragments (pp.29-51). Baltimore: Johns Hopkins University Press.

Schelling, F. W. J. (2006). Filosofía del arte. (V. López-Domínguez, trad.). Madrid: Tecnos. (Obra original publicada en 1802).

Schiller, F. y Goethe, J.W. (1881). Briefwechsel zwischen Schiller und Goethe (vol.1, 4a ed.). Stuttgart: Cotta. Recuperado de https://archive.org/details/ briefwechselzwi01schi

Schlegel, A.W. (1817). Ueber dramatische kunst und literature (vol.1). Heidelberg: Mohr und Winter. Recuperado de https://hdl.handle.net/2027/ nyp.33433082516877

Schlegel, A.W. (1817). Ueber dramatische kunst und literature (vol.3). Heidelberg: Mohr und Winter. Recuperado de https://hdl.handle.net/2027/ nyp.33433082516844

Schlegel, A.W. (1884). Vorlesungen über schöne litteratur und kunst (vol.3). Stuttgart: G.J. Göschen. Recuperado de https://archive.org/details/vorlesungenber03schluoft

Schlegel, A. W. y Schlegel, F. (1960). Athenaeum. Stuttgart: Cotta. Recuperado de https://hdl.handle.net/2027/uc1.b5246438

Schlegel, F. (1958). Kritische ausgabe seiner werke (vol.11). Múnich: F.Schöningh. 
Schlegel, F. (2005). Conversación sobre la poesía. (L.S. Carugati y S. Giron, trad.). Buenos Aires: Biblos. (Obra original publicada en 1800)

Shiner, L. E. (2004). La invención del arte: Una historia cultural. (E. Hyde y E. Julibert, trad.). Barcelona: Paidós. (Obra original publicada en 2001).

Tieck, L. (1828). Ludwig Tieck's schriften (vol.5). Berlín: Reimer. Recuperado de http://digital.bibliothek.uni-halle.de/hd/content/titleinfo/1861514

Tieck, L. (1828). Ludwig Tieck's schriften: Vol.10. Prinz Zerbino oder die reise nach dem guten geschmack. Berlín: Reimer. Recuperado de http://digital.bibliothek. uni-halle.de/hd/content/titleinfo/1861456

Tieck, L. (1843). Ludwig Tieck's schriften: Vol.16. Franz Sternbald's wanderungen. Berlín: Reimer. Recuperado de http://digital.bibliothek.uni-halle.de/hd/content/ titleinfo/1861397

Tollinchi, E. (1989). Romanticismo y modernidad: Ideas fundamentales de la cultura del siglo XIX. Río Piedras: Editorial de la Universidad de Puerto Rico.

Trahndorff, K.F.E. (1827). Aesthetik oder Lehre von der Weltanschauung und Kunst. Berlín: Maurer. Recuperado de https://archive.org/details/bub_gb_h54vAAAAYAAJ

Tymms, R. (1955). German romantic literature. Londres: Methuen.

Viñas, D. (2002). Historia de la crítica literaria. Barcelona: Ariel.

Wagner, R. (1850). Das kunstwerk der zukunft. Leipzig: O. Wigand. Recuperado de https://archive.org/details/bub_gb_tuxAAAAAcAAJ

Wagner, R. (1852). Oper und drama. Leipzig: J.J. Weber. Recuperado de https://hdl. handle.net/2027/nyp.33433075011266 
Wagner, R. (22 febrero, 1860). Une lettre à Hector Berlioz. Journal des débats politiques et littéraires. París. Recuperado de http://gallica.bnf.fr/ark:/12148/bpt6k452258x/f2.item.r=wagner

\section{¿Cómo citar este artículo?}

Aizpún Vílchez, I. (Enero-junio, 2018). La teoría de la obra de arte total como categoría formal en el primer Romanticismo alemán. Revista humanidades, 8(1), 25-50. doi: http://dx.doi.org/10.15517/h. v8i1.31464 